\title{
PALABRAS DE APERTURA: \\ ANTOLOGÍA NEWEN TXALCAN ZUGU / PALABRA DE FUERZA DE TRUENO ${ }^{1}$
}

La presente antología Newen Txalcan Zugu / Palabra de Fuerza de Trueno, asociada al dossier "Poesía mapuche" del presente número de la Revista Chilena de Literatura, reúne una selección de voces poéticas mapuche de creadoras y creadores que, a través del diálogo, se fueron configurando como un grupo autoseleccionado: Faumelisa Manquepillan Calfuleo, Leonel Lienlaf, Roxana Miranda Rupailaf, Jaime Luis Huenún Villa, Cristian Cayupan Mora, Kütral Vargas Huaiquimilla, Maribel Mora Curriao, David Aniñir Guilitraro, Javier Milanca Olivares, María Inés Huenuñir Antihuala y María Isabel Lara Millapan fueron invitadas e invitados a dar cuenta de la vitalidad de su propia creación poética a través de cinco obras, de las cuales escogí tres para conformar el corpus final. Algunos de los poemas son conocidos y emblemáticos y otros son inéditos. Sin embargo, lo que todos tienen en común es su capacidad para interpelar a la audiencia en relación con las distintas experiencias de vida dentro de la cosmovisión mapuche. En este sentido, la invitación es a escuchar las voces de cada poema, más allá de los estereotipos y prejuicios. Esto es especialmente relevante hoy en día, cuando el país está viviendo la paradoja de, por un, lado crecer y estar a la altura de elegir democráticamente y por primera vez una Convención Constitucional paritaria y con escaños reservados para los pueblos indígenas, y, por otro lado, estar ejerciendo violencia política contra el pueblo mapuche en el Wallmapu a través de la militarización y el Estado de Emergencia. El pueblo mapuche tiene una tradición de resolver los conflictos a través del diálogo, tal como 
lo evidencian los parlamentos diplomáticos con la Corona de España y luego con la República de Chile. En Chile debiéramos estar al día con los tratados internacionales de derechos humanos y resolver los asuntos políticos en el diálogo, no a través de la dominación y la violencia.

El pueblo mapuche es diverso y hay distintas posturas frente a la relación con el pueblo y el Estado de Chile, así como en relación con la Convención Constitucional. El bien común de las comunidades requiere de espacios abiertos para conocerse y combatir el racismo y los prejuicios. En este sentido, el presente dossier es un aporte a este diálogo, al ampliar los horizontes del entendimiento sobre la poesía mapuche, que, tal y como señala Jaime Huenún, está presente en nuestro campo cultural desde hace un tiempo considerable:

La poesía mapuche lleva casi tres décadas instalada en el sistema cultural chileno y hoy cuenta con más de cien autores en actividad. Desde su pluralidad aporta visiones, imaginarios y lenguajes que permiten ingresar a la cultura, historia, territorios y orígenes de las comunidades mapuche, urbanas y rurales. Tanto para la sociedad chilena como para los pueblos originarios, la poesía mapuche -y el arte indígena en general- contribuye a crear plataformas de conocimiento y de diálogo, de valoración cultural y de interacción desde distintas experiencias vitales, éticas y estéticas (párr. 4).

Otra diversidad que es fundamental considerar es la relación con las lenguas milenarias propias a los territorios y sus pueblos en la Abya Yala. No todas o todos los autores crecieron en hogares bilingües o tuvieron la posibilidad de aprender y vivir en el mapudungun de forma tal que sea la lengua desde donde surge la creación. La antología contiene poemas solo en español y otros que cuentan con versiones tanto en mapudungun como en español. Históricamente, la cultura oficial del Estado de Chile ha buscado exterminar las culturas milenarias, despojando a su población de su identidad y lengua, y desvalorizando sus culturas. Durante más de cien años, el Estado de Chile, sobre todo a través de las políticas educativas, buscó erradicar la lengua mapuche, con el resultado de que en muchos hogares se la dejara de cultivar para evitar el castigo y la discriminación. Hoy, cerca de un diez por ciento de la población mapuche es hablante activo. El actual dossier viene a contribuir a revertir esta lamentable realidad histórica y enriquecer la recepción, el entendimiento y la valorización de la cultura mapuche, incluyendo su lengua y creación verbal. 
Las y los poetas reflexionan frecuentemente sobre su propia experiencia para con la creación verbal en mapudungun. En uno de los foros del proyecto Encuentro con Mujeres Mapuche, marco en el cual se publicaron las antologías Hilando en la memoria (2006) e Hilando en la memoria. Epu Rupa (2009), la poeta Maribel Mora Curriao reivindica el hablar mapudungun como un derecho:

Creo que son una necesidad, un derecho y una reivindicación de nuestra lengua: el mapudungun. Decía en el otro foro [del encuentro] que yo no hablo el mapudungun, a pesar de que mis abuelos con quienes me crié si lo hablan y muchos de mis parientes. A nosotros nos quisieron ahorrar un sufrimiento en la escuela y se guardaron la lengua para conversaciones de adultos. Algo entiendo, reconozco palabras que cotidianamente oía, reconozco los fonemas, las fórmulas de saludo y diálogos breves. La universidad me ayudó con la escritura del mapudungun y por paradoja un profesor norteamericano: Bryan Harmelink, quien dictaba un curso de lengua y cultura mapuche en la Universidad de la Frontera en la década del noventa (cit. en Falabella 147).

Vemos cómo, para Mora Curriao, el rechazo del traspaso de la lengua al seno de su hogar era una forma de cuidado: "A nosotros nos quisieron ahorrar un sufrimiento en la escuela y se guardaron la lengua para conversaciones de adultos". La lengua en la infancia de la poeta es un estigma del cual se la protege y luego, cuando crece, toma contacto con esta carencia y la reivindica como un derecho fundamental del pueblo mapuche.

La reivindicación de la lengua como un derecho está hoy en el debate de la Nueva Constitución, al replantearnos Chile como un país plurinacional respetuoso de los derechos humanos, incluyendo los lingüísticos. Tal y como nos explica Elisa Loncon Antileo, Presidenta de la Mesa Directiva de la Convención Constitucional:

Los derechos lingüísticos son derechos humanos fundamentales, son transversales en materia de derechos humanos porque permiten el ejercicio de otros derechos como la adecuada atención de la salud, la educación, el acceso a la información y el debido proceso, entre otros (párr. 2). 
En efecto, requerimos del lenguaje para constituirnos como seres humanos y participar plenamente de la sociedad mediante el diálogo. Que un pueblo tenga una relación traumada por la violencia político-cultural con su lengua impacta su creación. Por ello, el campo de la literatura requiere hacerse cargo del estatus de los derechos humanos lingüísticos de las lenguas de las obras que estudia. Así mismo, David Aniñir Guilitraro señala:

No creo que el etiquetarte alguna clasificación étnica le suba el pelo a la creación literaria. [...] Mi obra representa principalmente al sentido de identidad mapuche en los espacios urbanos. Refiere al sentido de pertenencia a una nación, a su historicidad, su memoria colectiva y ciertos aspectos de la cosmovisión, todo ello aterrizado en la contemporaneidad y nuestro reality vivido como la primera y segunda generación mapuche nacida en la ciudad de Santiago, en mi caso (párr. 10).

Aniñir acuña el término "mapurbe" para nombrarse tanto a sí mismo como a la lengua-identidad que surge en "nuestro reality vivido como la primera y segunda generación mapuche nacida en la ciudad de Santiago."

La visión de Mora Curriao, en tanto, enfatiza la rebeldía que ella ejerce al no hablar ni escribir en mapudungun para significar la denuncia del despojo de la lengua que ha vivido el pueblo mapuche:

no escribo ni hablo en mapudungun por rebeldía, porque me interesa dejar constancia de la situación real de cientos de miles de mapuche que no conocen nada de su lengua. Yo tuve la suerte de conocerla a retazos, hilachas de una lengua como dice Huenún -que lucha por no desaparecer (cit. en Falabella 147).

Una lectura ingenua pasaría por alto la ausencia de una versión en mapudungun en la obra de una o un autor. Sin embargo, como vemos, este "silencio" es un grito a voces de una consciencia "que lucha por no desaparecer". En efecto, para comprender plenamente el sentido de la obra resulta fundamental conocer cuál es la relación de cada creadora y creador con su lengua originaria y la traducción.

En el mismo foro de diálogo de Hilando en la memoria, María Isabel Lara Millapan expresa su entendimiento sobre la escritura y la traducción en su proceso creativo: 
Mientras se escribe el lenguaje fluye en su estado más transparente, en el sentimiento más cercano. Escribo en mapudungun, también en español, pero son diferentes, cada idioma responde a las necesidades de su cultura. No se puede traducir literalmente, de hecho, lo que escribo en mapudungun, me cuesta mucho llevarlo al idioma español, porque cada palabra tiene su esencia, su identidad, se ha construido con sus únicas flores (cit. en Falabella 133-134).

En las palabras de Lara Millapan podemos apreciar cómo ella se entrega al flujo de ambas lenguas, dejando que sea el proceso creativo el que vaya indicando en cuál idioma surge la voz poética. Así, da cuenta de cómo ocurre en ella el fenómeno del cambio de código lingüístico, donde distinguimos la coexistencia del mapudungun y el español.

Por otro lado, la experiencia de Roxana Miranda Rupailaf con la lengua mapuche es diferente. En la siguiente intervención, la poeta reflexiona sobre su manera de vivir su relación con la traducción y el mapudungun:

Considero que la traducción es importante si queremos proteger una lengua. Admiro a las personas que escriben desde el mapudungun, yo no puedo hacerlo. Pero, aunque no lo hagamos; estar traducidas es importante porque además se crean puentes íntimos con los otros; los hablantes de la lengua.

La verdad es que a mí me cuestan mucho los idiomas, de alguna forma los sufro. Estuve un año en Alemania y me vi obligada por el contexto a aprender alemán. Y sentirse en otro lenguaje cambia las formas de ver y sentir. Se puede soñar en otros idiomas y es distinto el sueño y el temblor. Me gustaría que me pasara eso algún día con el mapudungun, pero no hay un contexto en el cual conjugar mis intereses académicos con un lenguajear neto de hablantes del idioma. Finalmente, uno siempre quisiera volver hacia atrás. Pero uno nunca se va a ser como se sueña. Creo que las cosas más trascendentes uno finalmente las vive en el lenguaje en que le enseñaron a latir y a pronunciar el mundo. Eso ya no se puede cambiar. Lo que hay que hacer es reencontrarse, hacer esfuerzos por aprender lo más que se pueda aquello que de nuestra cultura hemos perdido y (re) construir estos caminos para fortalecer el conocimiento de las futuras generaciones (cit. en Falabella 146).

Aquí vemos cómo para la poeta la traducción es importante porque su proceso de aprendizaje del mapudungun le ha costado. Ella tuvo la experiencia 
de aprender y lograr soñar en otra lengua cuando estudió en Alemania y sueña que eso le podría ocurrir en la lengua mapuche también. Sin embargo, piensa que lo importante es reencontrarse con la lengua y enseñársela a las nuevas generaciones.

Otro nudo propio de la creación verbal mapuche se relaciona con la oralidad. La tradición cultural mapuche comunica su sabiduría y su conocimiento a través de la tradición oral, donde al calor del fogón se comparte de forma comunitaria. La oralidad es la llave para abrir la puerta del entendimiento de la poesía, cuya performance se anticipa en una voz poética colectiva y dialógica, que vuelve a vincular al pueblo, convirtiéndose también en una instancia de espiritualidad. Hoy existe un debate abierto acerca de la relación de la oralidad y la escritura en las obras de creación verbal de los pueblos de la Abya Yala, incluyendo la creación verbal mapuche. ¿Acaso esta se constituye dentro del campo la literatura? ¿Se la puede llamar "creación literaria" o debemos emplear otro concepto para describirla? Elicura Chihuailaf habla de la "oralitura" conjugando la oralidad y la letra en una sola palabra: "En nuestras comunidades se continúa viviendo en el espíritu del ülkantün, que es la poesía cantada; nuestra poesía permanece fundamentalmente en la oralidad" (s/p). En efecto, el campo de la literatura tiene aún como desafío el desarrollar lenguaje y pensamiento crítico para describir y entender su coexistencia con las culturas de transmisión oral, en un contexto no solo de cultura letrada, sino que también digital. Aún está por delante comenzar a abrirse proactivamente a las otras culturas originarias y migrantes del territorio local y de la Abya Yala, para ponernos al día con nuestra propia realidad.

SoledAd FALABELLA Coordinadora de la antología Newen Txalcan Zugu / Palabra de Fuerza de Trueno Dossier: Poesía mapuche

Universidad de Chile sfalabella@uchile.cl 


\section{BIBLIOGRAFÍA}

Aniñir Guilitraro, David. "David Aniñir, el Rimbaud mapuche.” Entrevista con Marco Fajardo. El Mostrador (web), 22 de febrero de 2016, consultado el 19 de noviembre de 2021, disponible en: https:/www.elmostrador.cl/cultura/2016/02/22/david-aninir-el-rimbaud-mapuche-nocreo-que-el-etiquetarte-alguna-clasificacion-etnica-le-suba-el-pelo-a-la-creacion-literaria/

Chihuailaf, Elicura. "Oralitura". Memoria Chilena (web), consultado el 19 de noviembre de 2021, disponible en: http://www.memoriachilena.gob.cl/602/w3-printer-93536.html

Falabella, Soledad, Allison Ramay y Graciela Huinao (eds.). Hilando en la memoria: 7 mujeres mapuche. Santiago, Cuarto Propio, 2006.

Huenún, Jaime. "Jaime Luis Huenún, poeta: 'Todo lenguaje literario es político'”. Entrevista con María Jesús Blanche. Fundación La Fuente (web), 5 de enero de 2018, consultado el 19 de noviembre de 2021, disponible en: https://www.fundacionlafuente.cl/jaime-luishuenun-poeta-todo-lenguaje-literario-es-politico/

Loncon Antileo, Elisa. "Derechos lingüísticos de los pueblos indígenas y Nueva Constitución". El Mostrador (web), 19 de octubre de 2020, consultado el 19 de noviembre de 2021, disponible en: https:/www.elmostrador.cl/dia/2020/10/19/derechos-linguisticos-de-lospueblos-indigenas-y-nueva-constitucion/ 